\title{
The Active Immunity of the Person in Conditions of Anthropogenic Impact
}

\author{
${ }^{1}$ IInur F. Talipov, ${ }^{2}$ Irina D. Sitdikova, ${ }^{3}$ Elmira N. Mingazova,,${ }^{4}$ Dmitrii V. Lopushov, ${ }^{5}$ Lyubov A. \\ Balabanova \\ ${ }^{1,2,4}$ Kazan Federal University, Kazan, 420008, Russia, ${ }^{3}$ N. A. Semashko National Scientific Research \\ Institute of Public Health, 105064, Moscow, Vorontsovo Pole str. 12, ${ }^{5}$ Directorate of Rospotrebnadzor in \\ the Republic of Tatarstan, 420111, Kazan, Bolshaya Krasnaya str., bld.30
}

Email: ilnurtalipov09@mail.ru

Received: 15th December 2017, Accepted: 20th December 2017, Published: 31st December 2017

\begin{abstract}
The paper presents the results of the assessment of the military's immune system functioning subject to age and distribution by contingent using spontaneous and stimulated NBT-test. The primary study was conducted with distribution by contingent. A spontaneous NBT-test showed that the neutrophil count in blood was higher than normal in $72.1 \%$ of the soldiers, officers, and retired military personnel. The average result of the induced NST-test among the active servicemen and retired military personnel showed an excessive neutrophil level in $53.9 \%$ of cases. The paper also reflects the results of the analysis of the NBT-test taking into account the age of the servicemen. The comparative analysis of the NBT-test results revealed that $53.9 \%$ of the age groups of 18-29 years and 30-39 years has values higher than normal (statistically significant difference). The results of the spontaneous NBT-test exceeding the norm in the stimulated NBT-test indicate an excessive concentration of neutrophils in the blood, and a possible presence of a chronic inflammatory process and a violation of the phagocytic activity of the organism.
\end{abstract}

Keywords: Induced NBT-Test, Spontaneous NBTTest, Evaluation of Phagocytic Cells Function, Military Personnel, Contingent, Technogenesis.

\section{Introduction}

The conducted research in the field of public health and, in particular, medical services for servicemen, indicate the existence of a range of problems related to the health of draftees and contract servicemen [1, $2,3]$. The range of cause-effect relationships is revealed during the examination of the health status of retired servicemen [4, 5, 6, 7]. The state of morbidity indicators of servicemen, as well as the forecasts being built, indicate an increase in the incidence rate; the incidence of disability increases, the level of dismissal rate increases, and the death rate among military personnel decreases $[8,9]$. The legislative and regulatory level of the problem of medical care provides a coherent system of actions and consequences [10, 11]. However, currently, there is a lack of study of the problem level of health care such as personalized medicine [12,13,14]. Obviously, the assessment of the state of the immune system takes the central position in matters of personalized and preventive medicine $[15,16]$. At the present time, an essential level of knowledge is known for the formation of processes occurring in the human body, under the influence of environmental and production factors [17, 18, 19]. Ecological immunology distinguishes several stages of impairment and inhibition of the immune system. Determination of staging in immunological indices contributes to the development of a set of measures and the development of management decisions to reduce the impact of risk factors, the transition from one stage to another [20,21]. A variety of immunological indices form an urgent need to develop a complex of criteria that objectively describe the processes and changes [22].

Objective of the research: To evaluate the phagocytic activity of neutrophils by the spontaneous and induced nitro blue tetrazolium test in military personnel subject to their age and distribution by contingent.

\section{Methods}

The study involved 471 military personnel aged 18 years and over. The experimental group included active servicemen (work experience of more than 3 years), soldiers and retired military personnel. The control group included persons not related to military service. This group consisted of 368 people. For an objective assessment of the phagocytic activity of the body, blood sampling was performed only in persons with no signs of inflammatory diseases.

Instruments and materials: -StatFax 210® "StatFax" plate photometer, Voscher ${ }^{\circledR}$ "StatFax" thermostat shaker STZ, "Lenpipet" variable volume automatic pipettes of 20-1000 $\mu 1$, "Medpolimer" IFA flat plates.

Solutions and reagents: NBT "Sigma-Aldrich", autoclave-killed S.aureus suspension at a concentration of 1 million/ml, "PanEco" phosphatebuffered saline pH 7.4 tablets, DMSO 99\%, KOH "Sigma-Aldrich".

Indicators of the NBT-test (sNBT, iNBT) were defined as NBT $=\mathrm{D} \times 10000$, amount of $\mathrm{NF} \times 100$, where $\mathrm{D}$ is the optical density value directly determined by spectrophotometry, the amount of NF 
is the amount of neutrophils in $50 \mu$ of peripheral blood.

The obtained data were statistically processed by common methods on a PC using standard programs: STATISTICA 8.0, Microsoft Excel. As statistical tests we used single-factor analysis of variance for dependent groups (ANOVA test). A critical level of significance in checking statistical hypotheses was considered to be $\mathrm{p}=0.05$.

\section{Results}

Initially, the servicemen were distributed by contingent and divided into 3 experienced groups: rank and file, officers, retired military personnel. For each group, a spontaneous and induced NBT test was performed.

Spontaneous NBT-test allows assessing the bactericidal mechanism of phagocytes. The results show the distribution of the spontaneous NBT by the contingent in percent. The distribution can be either within the norm or not. Depending on the contingent, the percentage of the degree of risk varies, but amounts to $100 \%$ in total. The spontaneous test below the norm is observed only in $2.4 \%$ of soldiers, normal - in $25.3 \%$, higher than normal - in $72.3 \%$. At the same time, only $4.9 \%$ of retired servicemen have NBT-test results within the norm, and $95 \%$ of them have higher than normal values. In the group of active servicemen (officers), the NBT-test indicator was normal in $5.9 \%$, higher than normal - in $94.1 \%$.

For a reliable evaluation, the control group was also subject to the study. It included persons not related to military service. The obtained data showed that $97.3 \%$ of control subjects had normal values.

The induced NBT-test allows assessing the functional reserve of the oxygen-dependent bactericidal mechanism of phagocytes. The test is used to identify the reserve capacity of intracellular phagocyte systems. With preserved intracellular antibacterial activity in phagocytes, there is a sharp increase in the amount of formazan-positive neutrophils after their stimulation with latex. The distribution of induced NBT-test by contingent in a percentage ratio showed that the content of induced NBT-test is below the norm in retired servicemen. The activity of positive neutrophils was normal in $57.8 \%$ of the soldiers, $25.5 \%$ of officers, and $2.4 \%$ of retired officers. Higher than normal values of the induced test were found in $39.8 \%$ of soldiers, $72.5 \%$ of officers and $97.6 \%$ of retired military personnel. In the control group, $89.3 \%$ of subjects had values within normal range.

For a more detailed analysis, military personnel were divided according to their age. The results of the spontaneous NBT-test showed that in the first group of military personnel aged 18 to 29 years $2.2 \%$ of subjects had the level of positive neutrophils below the norm, $27.5 \%$ - normal, and $70.3 \%$ - above the norm. In the group with the age of 30 to 39 years, $22.7 \%$ of subjects had normal level, and $77.3 \%$ above the norm. The spontaneous NBT-test in the group of 40-49 years was normal in 20\% of subjects, and above the norm in $80 \%$. In the next group of 5059 years, normal values were observed in $42.9 \%$ of subjects, higher than normal - in $57.1 \%$. Normal values were revealed in $32 \%$ and above the norm in $68 \%$ of military personnel aged 60 to 69 years. In the group of 70 years and over, the excessive level was noted in $100 \%$ of subjects.

The induced NBT-test allows revealing the results of phagocytic activity. The normal NBT-test of positive neutrophils in adults with an induced NBT-test is 40$80 \%$.

The results of the induced NBT-test showed that in the first experimental group of military personnel aged 18 to 29 years $2.2 \%$ of subjects had values below the norm, $59.3 \%$ - normal, and $38.5 \%$ - above the norm. In the group of 30 to 39 years, $40.9 \%$ of subjects had normal values, $4.5 \%$ - below the norm, and $54.5 \%$ - above the norm. The induced NBT-test in the group of 40-49 years was normal in 36\% of subjects, and above the norm in $64 \%$. In the next group of 50-59 years, normal values were observed in $39.3 \%$ of subjects, higher than normal - in $60.7 \%$. Normal values were revealed in $32 \%$ and above the norm in $68 \%$ of military personnel aged 60 to 69 years. In the group of 70 years and over, the excess of normal values was noted in $100 \%$ of subjects.

The analysis found that in the comparative analysis of the NBT-test with regard to the age the values above the norm $(\rho=0.008)$, norm $(\rho=0,001)$, and below the norm $(\rho=0,005)$ constitute a statistically significant difference.

The statistics show that the indicator of the induced NBT-test subject to age by Pearson's criterion is as follows: $\mathrm{E} 2 \mathrm{a}=1.553$, the degree of freedom $\mathrm{n}^{\prime}=10$, $\chi 2=0.001$. According to Cramer's criterion, the value corresponds to the level of $\mathrm{CC}=0.513$ - medium association.

\section{Discussion}

This research paper was aimed at evaluating the phagocytic activity of neutrophils in the professional activity of military personnel with the help of the spontaneous and induced NBT-tests. The study involved 471 military personnel aged 18 years and over. The experimental group included active servicemen (work experience of more than 3 years), soldiers and retired military personnel. The control group included persons not related to military service. This group consisted of 368 people. For an objective assessment of the phagocytic activity of 
the body, blood sampling was performed only in persons with no signs of inflammatory diseases.

The phagocytic activity of neutrophils was evaluated by the spontaneous and induced nitro blue tetrazolium test in military personnel subject to their age and distribution by contingent.

An excessive neutrophil activity was recorded in more than $80 \%$ of cases, whose professional activities are associated with military service. The relationship between the age of military personnel and the violation of activity of neutrophil phagocytic activity was revealed. The immune system is the most complex human defense system, providing multi-stage protection against the surrounding damaging agents. Therefore, it is necessary to conduct further research and identify specific causes of excessive neutrophil activity in the body of servicemen.

\section{Summary}

1. Spontaneous and induced NBT-tests are objective indicators in the assessment of phagocytic activity of neutrophils in the conditions of professional activity of military personnel.

2. Distribution of the induced NBT-test by contingent showed that $70 \%$ of active servicemen have higher than normal phagocytic activity of neutrophils. In the control group, which included persons not related to military service, the values of NBT-test were normal in $89.3 \%$ of subjects. This indicates that military professional activity can have a direct effect on the phagocytic neutrophil activity.

3. The analysis of the induced NBT-test subject to age showed that with an increase in the age of the servicemen, the level of positive neutrophils increases too. After retirement, the figures decrease again.

4. The analysis of the spontaneous NBT-test subject to age showed that the highest excess of neutrophil count is observed among in the age group from 30 to 49 years.

\section{Conclusions}

The results of the studies described in this paper are devoted to the evaluation of active immunity parameters among the conscripted and contract servicemen and retired military personnel. These studies allow studying the state of the immune system over years. Significant and statistically reliable differences in the indicators of control and experience groups make it possible to assess the conditions of military service as risk factors. The studies show that the NBT-test (spontaneous and induced) objectively describes the processes in the immune system and can be recommended as a stage of immunological screening.

\section{Acknowledgements}

The work is performed according to the Russian Government Program of Competitive Growth of Kazan Federal University.

\section{References}

[1] Liuboshenko T.M. Study of the prevalence of secondary immune deficiencies among the population of the Russian Federation using cluster analysis // Modern problems of science and education. - 2014. - N 3; URL: www.scienceeducation.ru/117-13821 (accessed date: 18.04.2015).

[2] Iarilin A.A. Immunology. M.: GEOTAR-Media, 2010. - p. 752.

[3] Russian Statistical Yearbook. M.: Rosstat, 2014. - p. 693.

[4] Gevondian N.M., Alekhin A.I., Gevondian V.S. // A new form of secondary immunological failure and its role in the development of pathology. Allergology and Immunology. - 2014 (15). - N 3. p. 199.

[5] The angina-related limitations at work questionnaire / DJ.Lerner, B.C.Amick III, S.Malspeis et al. // Qual. Life Res. - 1998. - Vol. 7. P. 2332.

[6] The angina-related limitations at work questionnaire / DJ.Lerner, B.C.Amick III, S.Malspeis et al. // Qual. Life Res. - 1998. - Vol. 7. P. 2332.

[7] Luss L.V.// Quality of life. Medicine. - 2005. - N 4. - pp. 73-76.

[8] Gusakova N.V., Novikova I.A. Functional activity of neutrophils in chronic recurrent herpetic infection // Medical immunology. - 2013. - No. 2. pp. 169-176.

[9] Span P.N., Grebenchtchikov N.I., GeurtsMoespot A., Sweep C. G. J. Concerns about mammaglobin assays. // Clinical Chemistry. - 2005.v.51.- No.2,-p.474-75

[10] Perrotti M., Rabbani F., Russo P. et al. Early prostate cancer detection and potential for surgical cure in men with poorly differentiated tumors.// Urology. - 1998. - Vol.52. - P. 106-110.

[11] Kratnov A.E. The activity of glutathione reductase in neutrophils as an important marker of oxidative stress in ischemic heart disease // Russian Immunological Journal. - 2011. - No. 1. - pp. 45-49. [12] Koh H., Kattan M.W., Scardino P.T. et al. A nomogram to predict seminal vesicle invasion by the extent and location of cancer in systematic biopsy results.// J Urol. - 2003. - Vol. 170. - P. 1203-1208. [13] Kurzanov A.N., Slavinskii A.A., Titov M.I., Balachevskii B.V. Effect of activation of opiate receptors of neutrophilic leukocytes on their functional metabolic activity // Medical immunology. - 2007. - No. 3. pp. 148 -149.

[14] Green S., Kumar V., Krust A. et al. Structural and functional domains of the estrogen receptor. // 
Cold Spring HarbSymp Quant Biol. - 1986. - Vol. 51(Pt 2). - P. 751-758.

[15] Afzal MM, Jeshtadi A, Mohmmed AK. Study of neutrophilic function by nitrobluetetrazolium test in septicemias and immune deficiency diseases. Int $\mathbf{J}$ Res Health Sci. 2014 Apr 30; 2(2):581-90.

[16] Hyung Sim Choi, Jun Woo Kim , Young-Nam Cha \&Chaekyun Kim (2006) A Quantitative NitroblueTetrazolium Assay for Determining Intracellular Superoxide Anion Production in Phagocytic Cells, Journal of Immunoassay and Immunochemistry, 27:1, 31-44, Published online: 06 Feb 2007.

[17] Amarasekara D. S., Wijerathna S., Fernando C., Udagama P. V., Cost-effective diagnosis of male oxidative stress using the nitrobluetetrazolium test: useful application for the developing world Andrologia, 2014, 46, 73-79.

[18] Doherty, S.T. The situational risks of young drivers: the i nfluence of passengers, time of day and day of week on accident rates / S.T. Doherty, J.S. An-drey, C. MacGregor // Accid. Anal. Prev. - 1998. - Vol. 30, №1. - P. 45-52.

[19] Izmerov N.F. Health protection of workers and prevention of occupational diseases at the present stage // Labor medicine and industrial ecology. 2002. - No.1. - pp. 1-7

[20] Khaitov P.M., Pinegin B.V., Istamov Kh.I. Environmental immunology. - M., VNIRO, 1995. p. 219.

[21] Colwell A.R., Fenn G.K. Standards of practice of internal medicine: methods of judjing its quality in hospitals // Ann. intern. Med. - 1959. - Vol.51. P. 821-832.

[22] Elinidi V.N., Anikeeva N.V., Maksimova N.A. Practical immunocytochemistry (practical recommendations). - St. P.: Publishing house of the All-Russian Center for Extreme and Radiation Medicine of the Ministry of Emergencies of Russia, 2002. - p. 25. 